\title{
Cyclic changes in the responsiveness of regressing corpora lutea to the luteolytic effects of prolactin in rats
}

\author{
F. Gaytán ${ }^{1}$, C. Bellidoํ, C. Morales ${ }^{2}$ and J. E. Sánchez-Criado ${ }^{1}$ \\ ${ }^{1}$ Departments of Cell Biology, Physiology and Immunology, University of Córdoba, Spain; \\ and ${ }^{2}$ Department of Pathology, Faculty of Medicine, University of Córdoba, Spain
}

In cyclic rats, apoptosis of luteal cells during structural luteolysis occurs cyclically at the transition from pro-oestrus to oestrus in response to the preovulatory prolactin surge. This finding indicates that cyclic changes in apoptosis during luteolysis are dependent on prolactin surge cyclicity. In this study, the effects of prolactin on structural luteolysis were studied under different experimental conditions in relation to the phase of the oestrous cycle. In rats treated with prolactin at metoestrus and dioestrus, apoptosis did not occur in regressing corpora lutea, whereas in rats treated with prolactin on the morning of pro-oestrus, a 12.3-fold and 3.4-fold increase were observed in the number of apoptotic cells in regressing corpora lutea of the current and previous oestrous cycles, respectively. However, when the preovulatory prolactin surge and hence the subsequent apoptotic burst were blocked, prolactin treatment at the dioestrus phase induced a 13-fold increase in the number of apoptotic cells and significant changes in the volume of the corpus luteum $(38 \%$ decrease $)$ and the number of steroidogenic cells per corpus luteum $(70 \%$ decrease). The results of this study indicate that the responsiveness of the regressing corpus luteum to the pro-apoptotic effects of prolactin are dependent on the phase of the oestrous cycle and on the presence or absence of an apoptotic burst in response to the preovulatory prolactin surge on the evening of pro-oestrus. Steroidogenic cells surviving to the apoptotic burst during the transition from pro-oestrus to oestrus became refractory to the lytic effect of prolactin. Furthermore, these cells also responded to the luteotrophic effects of prolactin, reaching full morphological luteinization, as indicated by the rescue of regressing cyclic corpora lutea during pregnancy.

\section{Introduction}

Structural luteolysis is responsible for the elimination of luteal cells in the non-functional corpus luteum. In cyclic rats, apoptosis of luteal cells is the first morphological sign of structural luteolysis (Bowen et al., 1996; Gaytán et al., 1998, 2000). In rats, it is well established that apoptosis is triggered by the preovulatory prolactin surge on the evening of pro-oestrus (Bowen et al., 1996; Gaytán et al., 1998, 2000). Structural luteolysis can be induced in hypophysectomized (Malven and Sawyer, 1966; Malven, 1969; Malven et al., 1969; Bowen et al., 1996) or cyclic (Wuttke and Meites, 1971; Bowen et al., 1999; Gaytán et al., 2000) rats by exogenous administration of prolactin. In contrast, structural luteolysis can be inhibited by blocking the preovulatory prolactin surge with the dopaminergic agonist CB154 (Billeter and Flückiger, 1971; Gaytán et al., 1998). These data indicate that prolactin is the main hormone controlling luteolysis in rats.

However, apoptosis does not occur as a continuous process during corpus luteum regression. Other studies have shown that apoptotic DNA fragmentation occurs cyclically during the transition from pro-oestrus to oestrus (Matsuyama et al., 1996) and that the increase in apoptosis

Email: fi1begac@lucano.uco.es at this time affects the different generations of corpora lutea (Bowen et al., 1999). In this context, four to five oestrous cycles are required for the complete elimination of nonfunctional corpora lutea. In cyclic rats, the prolactin surge occurs exclusively on the evening of pro-oestrus (Smith et al., 1975) and the low rate of apoptosis that occurs during the dioestrous phase of the oestrous cycle seems to be due to the lack of prolactin surges at this time. However, whether the stage of the oestrous cycle has any relevant affect on prolactin-induced apoptosis in cyclic rats has not been established.

Prolactin is also the main luteotrophic hormone during the first half of pregnancy in rats (Morishige et al., 1973; Niswender et al., 1994). Therefore, this hormone plays a dual role depending on the functional status of the corpus luteum: prolactin is luteotrophic in functional corpora lutea and luteolytic in non-functional corpora lutea (Malven and Sawyer, 1966; Malven, 1969; Rothchild, 1981). It is widely assumed that prolactin is always luteolytic in the nonfunctional corpus luteum, and that the effect of prolactin is irreversible, and that the rate at which corpora lutea regress is related to prolactin concentrations (Malven and Sawyer, 1966; Richards and Williams, 1976). However, a study by Bruce et al. (1984) focused on the changes in blood flow during pregnancy in rats. This study revealed that regressing corpora lutea of previous oestrous cycles have increased 
blood flow and luteal tissue mass similar to those in the corpus luteum of pregnancy from day 13 of pregnancy onwards. The fact that prolactin concentrations are considerably increased during the first half of pregnancy (Amenomori et al., 1970; Morishige et al., 1973) raises questions about the prolonged luteolytic effects of prolactin on regressing corpora lutea, as well as on the reversibility of the structural luteolytic process.

The aim of this study was to analyse further the luteolytic effects of prolactin on the regressing corpus luteum in different physiological and experimental conditions related to different phases of the oestrous cycle in an attempt to clarify the apparently paradoxical effects of prolactin in non-functional corpora lutea.

\section{Materials and Methods}

\section{Animals and treatments}

Female Wistar rats (about $200 \mathrm{~g}$ body weight) were purchased from Panlab (Barcelona). They were maintained under controlled light ( $14 \mathrm{~h}$ light:10 h dark, lights on at 05:00 h) and temperature $\left(21-22^{\circ} \mathrm{C}\right)$ conditions, and had free access to rat chow and tap water. Vaginal smears were taken each day and only those animals displaying at least two consecutive 4 day oestrous cycles were used in the experiments.

The dopaminergic agonist 2-bromo- $\alpha$-ergocryptine (CB154) that specifically inhibits prolactin secretion was purchased from Sandoz (Basel). The GnRH antagonist used was ORG.30276 (Ac-D-p-Cl-Phe-D-p-Cl-Phe-D-Trp-Ser-TyrD-Arg-Leu-Arg-Pro-D-Ala- $\mathrm{NH}_{2} \cdot \mathrm{CH}_{3} \cdot \mathrm{COOH}$ ) (Organon, Oss). Ovine prolactin (oprolactin-18) was obtained from the NIADDK (Baltimore, MD).

\section{Experimental designs}

Experiment 1. The objective of this experiment was to analyse the short-term response of non-functional corpora lutea to administration of prolactin on different days of the oestrous cycle. Cyclic rats were injected in the morning $(10: 00 \mathrm{~h})$ at pro-oestrus, metoestrus or dioestrus with prolactin $\left(250 \mu \mathrm{g}\right.$ per rat) or vehicle $\left(0.03 \mathrm{~mol} \mathrm{NaHCO}_{3} \mathrm{I}^{-1}\right.$, $0.15 \mathrm{~mol} \mathrm{NaCl} \mathrm{I-1}, 0.5 \%(\mathrm{w} / \mathrm{v}) \mathrm{BSA}, \mathrm{pH}$ 9), and were then killed at 180 min after treatment (five animals per group). Gaytán et al. (2000) reported that this dose of prolactin significantly increased apoptotis at $180 \mathrm{~min}$ after treatment. The ovaries from the right side of rats were fixed in BouinHollande's fluid for $24 \mathrm{~h}$ at room temperature and the ovaries from the left side of rats were fixed in $4 \%(\mathrm{w} / \mathrm{v})$ paraformaldehyde for $24 \mathrm{~h}$ at $4^{\circ} \mathrm{C}$. All ovaries were then processed for embedding in paraffin wax. Sections of the ovaries $(5 \mu \mathrm{m})$ were stained with haematoxylin and eosin to determine the number of apoptotic cells in the last two generations of regressing corpora lutea. In some paraformaldehyde-fixed ovaries, the TUNEL method for the in situ detection of DNA fragmentation was applied as described by Gaytán et al. $(1998,2000)$.
Experiment 2. The objective of this experiment was to analyse whether the lack of response of non-functional corpora lutea in rats during dioestrous phase to prolactin (indicated by the results of Expt 1) was dependent on the presence of a previous prolactin-induced apoptotic burst at pro-oestrus. Initially, changes in corpus luteum volume and in the number and size of steroidogenic luteal cells in rats treated several times with prolactin during the dioestrous phase were quantified. Cyclic rats were injected (09:00 h) at the pro-oestrous and metoestrous phases with the GnRH antagonist ( $0.5 \mathrm{mg}$ per rat in saline) to prevent ovulation and hence formation of new corpora lutea, or with vehicle. In addition, proestrous rats were injected at 10:00 h with $1 \mathrm{mg}$ CB154 per rat to block the preovulatory prolactin surge or with vehicle $(70 \%(\mathrm{v} / \mathrm{v})$ ethanol). At the subsequent metoestrus and dioestrus, animals were injected with prolactin $(250 \mu \mathrm{g}$ per rat) or vehicle twice each day (at 10:00 $\mathrm{h}$ and 19:00 h). On the day after the last injection (corresponding to the day of pro-oestrus in vehicle-injected rats), five animals per group were killed (at 10:00 h). Ovaries were processed as in Expt 1, and the ovaries from the right side of rats were cut into serial sections $5 \mu \mathrm{m}$ in thickness.

Experiment 3. The objective of this experiment was to investigate the morphological and quantitative changes throughout pregnancy in both the corpus luteum of pregnancy and in the regressing corpus luteum of the previous oestrous cycle. Pregnant rats were hemiovariectomized on days 3, 6, 9, 12, 15, 17, 19 and 21 of pregnancy (three rats per day). The ovaries were fixed in Bouin-Hollande's fluid, embedded in paraffin wax and cut into sections $5 \mu \mathrm{m}$ in thickness. The cross-sectional area of steroidogenic cells was determined in both the corpus luteum of pregnancy and the regressing corpus luteum of the previous oestrous cycle.

\section{Cell counting and stereological study}

Apoptotic cells were counted using methods described by Gaytán et al. (1998, 2000). Briefly, stained cells were counted under $\mathrm{a} \times 100$ objective in three different sections per corpus luteum and in three different corpora lutea per rat from each generation of corpora lutea. Each section of the corpus luteum was scored systematically and the number of apoptotic nuclei was expressed per unit area of luteal tissue. The presence of fragmented DNA during prolactin-induced luteolysis was also confirmed by staining with TUNEL method.

The volume of the corpus luteum was obtained by measuring two diameters at right angles under a $\times 4$ objective in the largest corpus luteum section, in at least five different corpora lutea per ovary from each generation of corpora lutea. The cross-sectional area of the steroidogenic cells was obtained by point counting with the aid of a 121 test-point reticle $\left(16000 \mu \mathrm{m}^{2}\right)$ incorporated into the microscope. At least 100 steroidogenic cell sections showing 
the nucleolus were measured per animal and for each corpus luteum generation. The number of steroidogenic cells per corpus luteum was obtained by the nucleator method (Gundersen et al., 1988; Sharpe et al., 2000). The volume density of steroidogenic cell nuclei $\left(V v_{\mathrm{n}}=P_{\mathrm{i}} / P_{\mathrm{t}}\right)$ was obtained by point counting with a 121 test-point reticle, as the proportion of test points counted on cell nuclei. The product of $V v_{n}$ by the corpus luteum volume gives the absolute volume occupied by steroidogenic cell nuclei per corpus luteum $\left(V_{n}\right)$. In each steroidogenic cell nuclear section showing the nucleolus, four separate radii $\left(I_{\mathrm{i}}\right)$ were measured from the nucleolus to the nuclear membrane using a micrometer eyepiece incorporated into the microscope under $\times 100$ objective, in at least 100 steroidogenic cells per rat and for each generation of corpora lutea. The unbiased mean volume of the steroidogenic cell nuclei was $\bar{v}_{\mathrm{n}}=(4 \pi / 3)\left[\left(I_{1}^{3}+I_{2}^{3}+I_{3}^{3}+I_{4}^{3}\right) / 4\right]=(4 \pi / 3) I_{\mathrm{i}}^{3}$. By dividing $V_{\mathrm{n}}$ by $\bar{v}_{\mathrm{n}}$ the number of steroidogenic cells per corpus luteum was obtained.

Data are presented as mean \pm SEM. Statistical analyses were performed by ANOVA and Tukey's test for multiple comparison among means, or by Student's $t$ test if only two means had to be compared.

\section{Results}

Experiment 1: response of the regressing corpus luteum to prolactin treatment on the different days of the oestrous cycle

Quantitative data for rats injected with prolactin or vehicle at different days of the oestrous cycle are shown (Fig. 1). In rats at metoestrus and dioestrus, the corpus luteum of the current oestrous cycle corresponded to a functional corpus luteum and apoptosis was almost absent. In rats at prooestrus, the corpus luteum of the current oestrous cycle was non-functional and apoptosis was scarce in vehicle-treated rats. Prolactin treatment did not induce apoptosis in rats at metoestrus or dioestrus, but it did induce a 12.3-fold increase in the number of apoptotic cells on the morning of prooestrus. In corpora lutea of the previous oestrous cycle, the number of apoptotic cells was not modified in rats treated with prolactin at metoestrus or dioestrus, but there was a 3.4fold increase in the number of apoptotic cells at pro-oestrus.

\section{Experiment 2: effects of prolactin treatment during the dioestrous phase on regressing cyclic corpora lutea}

In rats treated with the $\mathrm{GnRH}$ antagonist, ovulation was blocked and corpora lutea of the current oestrous cycle were absent. Therefore, the youngest corpus luteum generation corresponded to that of the previous oestrous cycle. Quantitative data are presented (Fig. 2). Rats treated with vehicle at the previous pro-oestrus had smaller corpora lutea (about 50\%) and contained fewer (about 75\%) steroidogenic cells than did those injected with CB154. This finding indicates the presence of a previous physiological prolactin surge in GnRH antagonist-treated rats, as

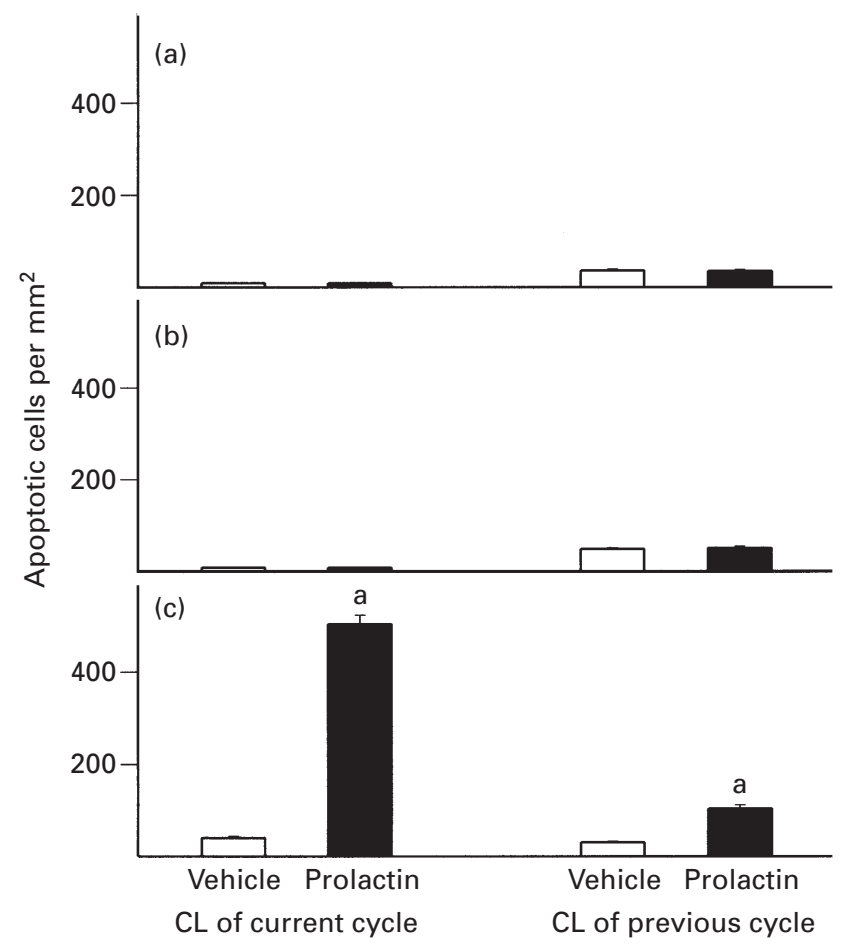

Fig. 1. The number of apoptotic cells in cyclic corpora lutea $(\mathrm{CL})$ of the current and previous oestrous cycles at $180 \mathrm{~min}$ after treatment with vehicle $(\square)$ or prolactin $(\square)$ in rats at (a) metoestrus, (b) dioestrus or (c) pro-oestrus. ${ }^{a}$ Values are significantly different from vehicle treatment $(P<0.01)$. ANOVA and Tukey's test were used $(n=5)$.

structural luteolysis during the transition from pro-oestrus to oestrus is triggered by the prolactin surge. Furthermore, the prolactin surge is dependent exclusively on the increasing titre of oestrogen at dioestrus through to early pro-oestrus (Freeman, 1988), before GnRH administration on the morning of pro-oestrus.

In rats treated with vehicle on the morning of pro-oestrus, the administration of prolactin did not significantly affect either the number of apoptotic cells or the number of steroidogenic cells per corpus luteum, although there was a slight decrease in the corpus luteum volume. Conversely, in rats in which the preovulatory prolactin surge (and therefore the first apoptotic burst) was blocked by treatment with CB154 at the previous pro-oestrus, administration of prolactin at dioestrus significantly increased (13-fold) the number of apoptotic cells and resulted in a significant decrease in both the volume of the corpus luteum (38\%) and the number of steroidogenic cells per corpus luteum $(70 \%)$. The cross-sectional area of steroidogenic cells was not significantly different in any group.

\section{Experiment 3: changes in the different types of corpus luteum during pregnancy}

On day 3 of pregnancy, corpora lutea from the previous oestrous cycle had similar morphology to regressing 

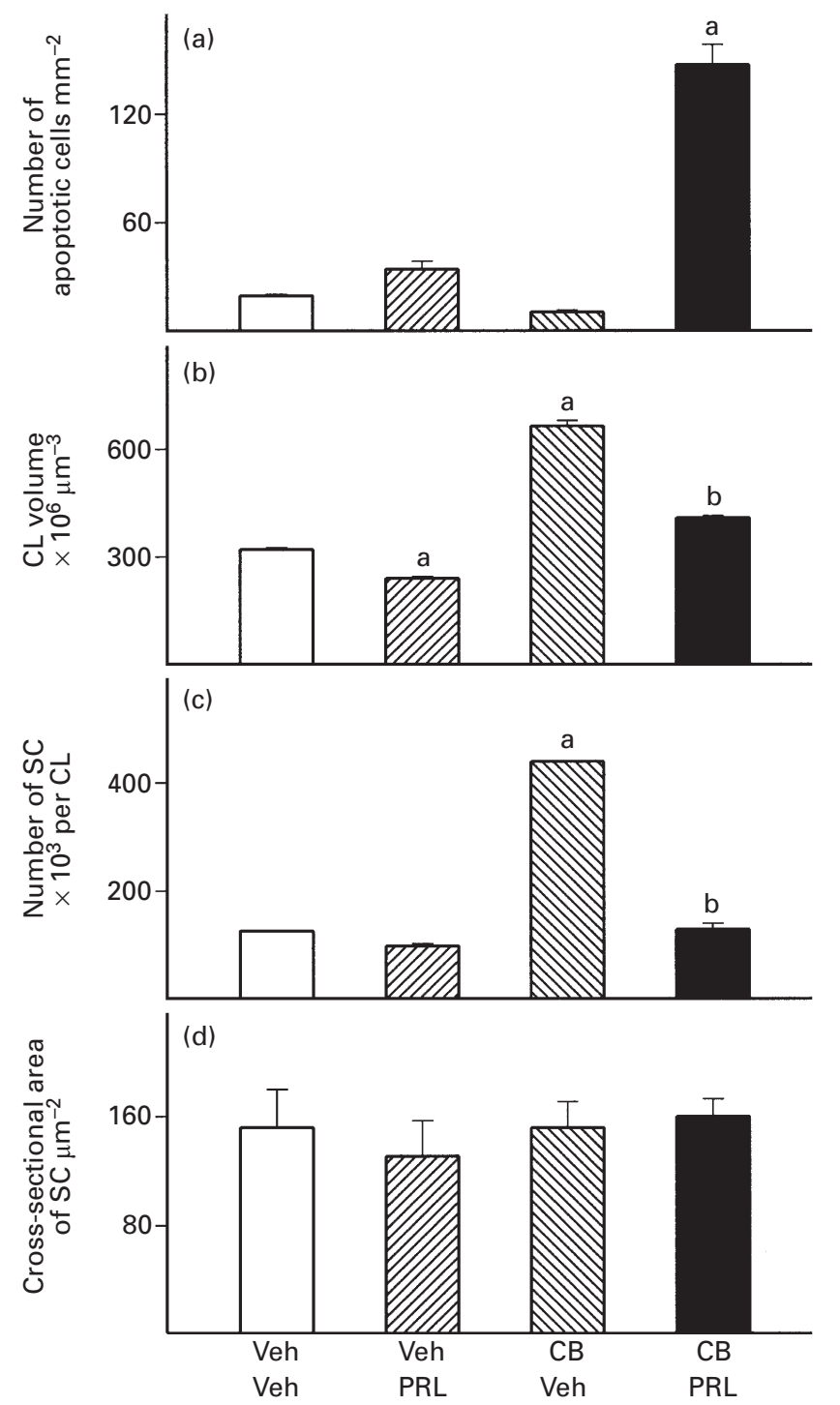

Fig. 2. (a) The number of apoptotic cells, (b) corpora lutea (CL) volume, (c) number of steroidogenic cells (SC) per corpus luteum and (d) cross-sectional area of steroidogenic cells in rats treated at pro-oestrus with vehicle and at dioestrus with vehicle (VehVeh; $\square$ ); or with vehicle and prolactin (VehPRL; $\mathbb{Z}$ ) or with 2-bromo- $\alpha$ ergocryptine (CB154) at pro-oestrus and at dioestrus with CB154 and vehicle (CBVeh $\mathbb{N})$; or with CB154 and prolactin (CBPRL; $\mathbf{\square})$. ${ }^{a}$ Values are significantly different from VehVeh treatment $(P<0.01)$. ${ }^{b}$ Values are significantly different from CBVeh treatment $(P<0.01)$. ANOVA and Tukey's test were used $(n=5)$.

corpora lutea. These corpora lutea were small, and had large steroidogenic cells and a large proportion of nonsteroidogenic cells (Fig. 3a). Corpora lutea of pregnancy were easily identified because of their marked vascular pattern, non-fully luteinized steroidogenic cells and a small proportion of non-steroidogenic cells (Fig. 3b). During pregnancy, there was a progressive increase in the size of steroidogenic cells in both the corpus luteum of pregnancy and the regressing cyclic corpus luteum (Fig. 3c-f). This was particularly evident from day 9 to day 19 , when steroidogenic cells had large nuclei with prominent nucleoli and large granulated cytoplasm (Figs 3c-f). Regressing cyclic corpora lutea were considerably smaller than corpora lutea of pregnancy (Fig. 3c), although they had enlarged steroidogenic luteal cells and a larger proportion of non-steroidogenic cells (Fig. 3d,f). Mitotic steroidogenic cells were observed in both rescued cyclic corpus luteum (Fig. 3f) and corpus luteum of pregnancy (Fig. 3g). Quantitative data for the size of steroidogenic cells are shown (Fig. 4). The cross-sectional area of steroidogenic cells increased 2.3-fold in corpus luteum of pregnancy on days 9-19 of pregnancy. The growth of steroidogenic cells in the regressing corpus luteum of the previous oestrous cycle was almost the same as that in the corpus luteum of pregnancy $(2.1$-fold increase in the cross-sectional area of steroidogenic cells during the same period).

\section{Discussion}

It is well established that prolactin acts as a luteolytic factor in regressing (non-functional) corpora lutea in the rat (Wuttke and Meites, 1971; Bowen et al., 1999; Gaytán et al., 2000). In the present study, the response of regressing corpora lutea to prolactin was dependent on the stage of the oestrous cycle. Prolactin induced apoptosis of the luteal cells in rats at pro-oestrus, but it did not induce apoptosis in rats at metoestrus and dioestrus. This finding indicates that there are cyclic changes in the sensitivity of the regressing corpus luteum to the pro-apoptotic effects of prolactin.

The lack of the luteolytic effects of prolactin in dioestrus was dependent on a previous endogenous prolactininduced apoptotic burst during the transition from pro-oestrus to oestrus. In those animals in which the preovulatory prolactin surge occurred at the previous prooestrous phase, and hence the corpus luteum underwent the first physiological apoptotic burst, prolactin treatment at the dioestrous phase did not significantly increase apoptosis. In addition, the number of steroidogenic cells per corpus luteum did not significantly change, although the volume of the corpus luteum was decreased slightly. This finding could be due to changes in the volume of the vascular space or to a slight increase in apoptosis under the detection limit of this study. However, in those animals in which the prolactin surge was blocked with CB154 and, therefore, the first physiological apoptotic burst was prevented, prolactin administration at the dioestrous phase resulted in a significant increase in the number of apoptotic cells and a decrease in both the corpus luteum volume and the number of steroidogenic cells. These results indicate strongly that steroidogenic luteal cells surviving to the prolactin-induced apoptotic burst are not sensitive to the pro-apoptotic effects of prolactin during dioestrus. As in cyclic rats, a new round of apoptosis occurs after the transition from pro-oestrus to oestrus (Bowen et al., 1999), progression through the dioestrous phase seems necessary 


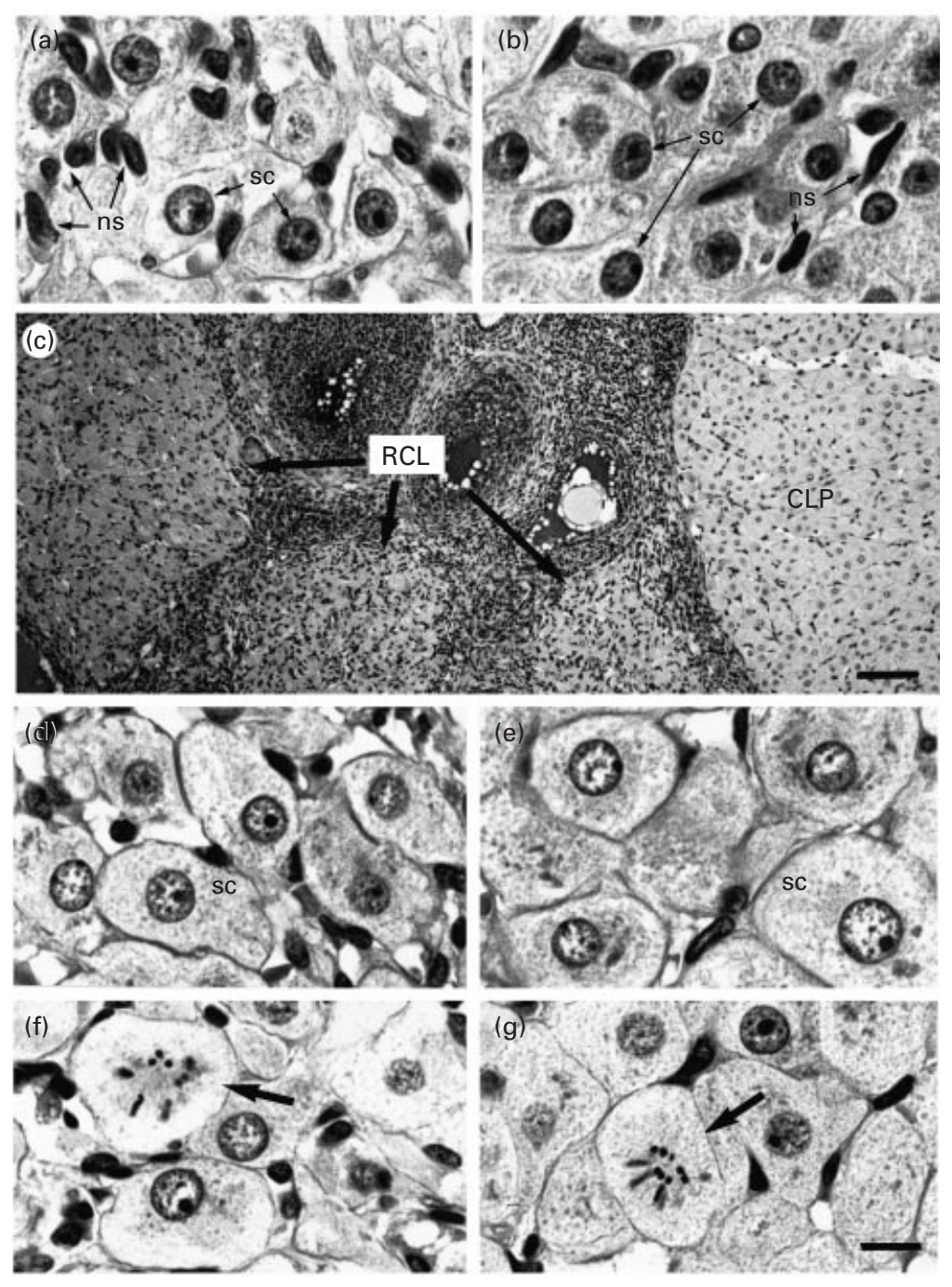

Fig. 3. Morphological changes in corpora lutea of pregnancy and in regressing corpora lutea of the previous oestrous cycle in rats. On day 3 of pregnancy, regressing corpora lutea of the previous oestrous cycle (a) showed a higher ratio of non-steroidogenic (ns) : steroidogenic (sc) cells compared with corpora lutea of pregnancy (b). (c) On day 19 of pregnancy, large corpora lutea of pregnancy (CLP) and smaller rescued cyclic corpora lutea (RCL) were observed. (d) and (e) Areas of rescued cyclic corpus luteum (d) and corpora lutea of pregnancy (e) correspond to tissues in (c) at a greater magnification and show large fullyluteinized steroidogenic cells (sc). Mitotic steroidogenic cells (arrows) can be observed in both rescued cyclic corpora lutea (f) and corpora lutea of pregnancy (g). Scale bars represent (a,b,d-g) $9 \mu \mathrm{m}$ and (c) $90 \mu \mathrm{m}$.

for the recovery of responsiveness to the pro-apoptotic effects of prolactin. The lack of response of regressing corpora lutea to prolactin treatment during metoestrus and dioestrus indicates that unresponsiveness to short-term prolactin treatment (Expt 1) was not due to a slower response in older corpora lutea.

The mechanisms responsible for cyclic changes in the sensitivity of regressing corpora lutea to the pro-apoptotic effects of prolactin are unknown. A possible explanation is that part of the luteal cell population becomes responsive to the pro-apoptotic effects of prolactin during dioestrus. This subpopulation of luteal cells undergoes apoptosis in response to the preovulatory prolactin surge. The remaining luteal cells are not sensitive to the lytic effects of prolactin and, therefore, progression through the dioestrous phase in the following oestrous cycle is required for the acquisition of prolactin responsiveness by some, but not all, luteal cells. In this manner, the regressing corpus luteum should 


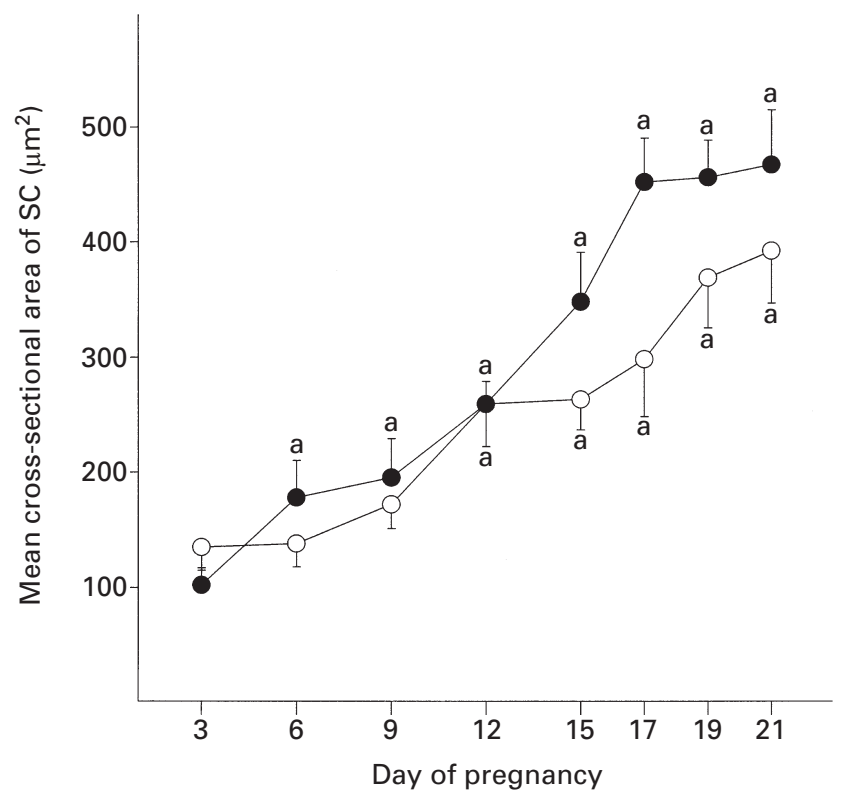

Fig. 4. Increase in the cross-sectional area of steroidogenic luteal cells (SC) in the corpora lutea during pregnancy $(-)$ and in rescued

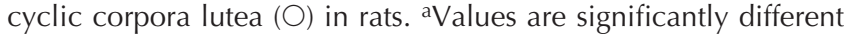
from values on day 3 of pregnancy $(P<0.01)$. ANOVA and Tukey's test were used $(n=3)$.

progress through four to five successive oestrous cycles to be completely eliminated. This contention would explain why when the apoptotic burst does not occur (by blocking preovulatory prolactin surge), prolactin-sensitive cells remain in the corpus luteum and undergo apoptosis in response to the exogenous prolactin at dioestrus.

The loss of responsiveness to the pro-apoptotic activity of prolactin in regressing corpora lutea after the apoptotic burst was also supported by the activation of the remaining steroidogenic cells in regressing cyclic corpora lutea of pregnancy. Gaytán et al. (1997a) indicated that regression of non-functional corpora lutea of previous oestrous cycles was initially accelerated on the first days of pregnancy due to two prolactin surges each day induced by mating. Regression of these corpora lutea should occur in response to the first prolactin surges in pro-oestrus and oestrus, when the corpus luteum is still sensitive to the pro-apoptotic actions of prolactin, and which could explain the small size of rescued corpus luteum. However, if regressing corpora lutea continue to be responsive to the deleterious effects of prolactin, they would be completely eliminated during the first week of pregnancy by the two prolactin surges each day induced by mating (Smith et al., 1975). In contrast, the remaining steroidogenic luteal cells in the corpus luteum of the previous oestrous cycle resumed the luteal differentiation pathway. The results of the present study indicate that the growth pattern of steroidogenic cells in both the resuced corpus luteum and the corpus luteum of pregnancy was parallel to serum progesterone concentrations (Morishige et al., 1973). Furthermore, steroidogenic cells of the rescued corpus luteum showed proliferative activity at specific stages of pregnancy, as occur in the corpus luteum of pregnancy (Gaytán et al., 1997b), and reached full morphological luteinization. This finding is in agreement with a study by Bruce et al. (1984) in which a significant increase in the blood flow and luteal tissue mass during pregnancy in corpora lutea of previous oestrous cycles was reported. Although the morphology of these cells indicated that they were steroidogenically active, the functional status of rescued corpora lutea cannot be ascertained from the results of the present study. The constancy of steroidogenic cell size in those cells surviving to the apoptotic burst also indicates that they do not undergo important degenerative changes and that they are potentially able to complete luteinization.

Structural luteolysis started after the functional decay of the corpus luteum, and seems to be necessary to avoid accumulation of non-functional luteal tissue. It is possible that apoptotic bursts associated with ovulatory events probably evolved as a mechanism for fast deletion of steroidogenic cells in non-functional, but still recoverable, luteal tissue. In the absence of the preovulatory prolactininduced apoptotic burst, at least two generations of fully luteinized corpora lutea would be present during pregnancy, as a result of the rescue of regressing corpora lutea of the previous oestrous cycle.

In summary, during structural luteolysis in the rat, prolactin-induced apoptosis of luteal cells occurs cyclically at the transition from pro-oestrus to oestrus. After each apoptotic burst, the remaining luteal cells become refractory to the lytic effects of prolactin, and progression through dioestrus of the subsequent oestrous cycle is required to recover prolactin responsiveness. Furthermore, the remaining luteal cells are able to respond luteotrophically, reaching full morphological luteinization under appropriate stimulation (that is, during pregnancy).

The authors are very grateful to J. Molina, P. Cano, T. Recio and E. Tarradas for their technical assistance. This work has been subsidized by Grants (1FD97-1065-C03-03 and PM98-0167) from the DGESEIC, Spain.

\section{References}

Amenomori Y, Chen CL and Meites J (1970) Serum prolactin levels in rats during different reproductive states Endocrinology 86 506-510

Billeter E and Flückiger E (1971) Evidence for a luteolytic function of prolactin in the intact cyclic rat using 2-Br- $\alpha$-ergokryptine (CB154) Experientia 27 464-465

Bowen JM, Keyes PL, Warren JS and Townson DH (1996) Prolactininduced regression of the rat corpus luteum: expression of monocyte chemoattractant protein-1 and invasion of macrophages Biology of Reproduction 54 1120-1127

Bowen JM, Towns R, Warren JS and Keyes PL (1999) Luteal regression in the normally cycling rat: apoptosis, monocyte chemoatractant protein-1 and inflammatory cell involvement Biology of Reproduction $60740-746$

Bruce NW, Meyer GT and Dharmarajan AM (1984) Rate of blood flow and growth of the corpora lutea of pregnancy and of previous cycles throughout pregnancy in the rat Journal of Reproduction and Fertility 71 445-452

Freeman ME (1988) The ovarian cycle of the rat. In The Physiology of Reproduction pp 1893-1928 Eds E Knobil and JD Neill. Raven Press, New York 
Gaytán F, Morales C, Bellido C, Aguilar E and Sánchez-Criado JE (1997a) Role of prolactin in the regulation of macrophages and in the proliferative activity of vascular cells in newly formed and regressing rat corpora lutea Biology of Reproduction 57 478-486

Gaytán F, Bellido C, Morales C, Aguilar E and Sánchez-Criado JE (1997b) Evidence for steroidogenic luteal cell hypertrophy and hyperplasia during pregnancy in the rat Journal of Endocrinology 154 211-217

Gaytán F, Bellido C, Morales C and Sánchez-Criado JE (1998) Both prolactin and progesterone are necessary for the induction of apoptosis in the regressing corpus luteum of the rat Biology of Reproduction 59 1200-1206

Gaytán F, Morales C, Bellido C, Aguilar R, Millan Y, Martin de las Mulas J and Sánchez-Criado JE (2000) Progesterone on and oestrogen background enhances prolactin-induced apoptosis in regressing corpora lutea in the cyclic rat: possible involvement of luteal endothelial cell progesterone receptor Journal of Endocrinology 165 715-724

Gundersen HJG, Bagger P, Bendtsen TF et al. (1988) The new stereological tools: dissector, fractionator, nucleator, and point sampled intercepts and their use in pathological research and diagnosis Acta Pathologica, Microbiologica et Immunologica Scandinavica 96 857-881

Malven PV (1969) Luteotrophic and luteolytic responses to prolactin in hypophysectomized rats Endocrinology 84 1224-1229

Malven PV and Sawyer CH (1966) A luteolytic action of prolactin in hypophysectomized rats Endocrinology 79 268-274

Malven PV, Cousar GJ and Row EH (1969) Structural luteolysis in hypophysectomized rats American Journal of Physiology 216 421-424

Matsuyama S, Chang KT, Kanuka H, Ohnishi M, Ikeda A, Nishihara M and Takahashi M (1996) Occurrence of the deoxyribonucleic acidfragmentation during prolactin induced structural luteolysis in cycling rats Biology of Reproduction 54 1245-1251
Morishige WK, Pepe GJ and Rothchild I (1973) Serum luteinizing hormone, prolactin and progesterone levels during pregnancy in the rat Endocrinology 92 1527-1530

Niswender GD, Juengel JL, McGuire WJ, Belfiore CJ and Wiltbank MC (1994) Luteal function: the estrous cycle and early pregnancy Biology of Reproduction 50 239-247

Richards JS and Williams JJ (1976) Luteal cell receptor content for prolactin (PRL) and luteinizing hormone (LH): regulation by $\mathrm{LH}$ and PRL Endocrinology 99 1571-1581

Rothchild I (1981) The regulation of the mammalian corpus luteum Recent Progress in Hormone Research 37 183-295

Sharpe RM, Walker M, Millar MR, Atanassova N, Morris K, McKinnell C, Saunders PTK and Fraser HM (2000) Effect of neonatal gonadotropinreleasing hormone antagonist administration on Sertoli cell number and testicular development in the marmoset: comparison with the rat Biology of Reproduction 62 1685-1693

Smith MS, Freeman ME and Neill JD (1975) The control of progesterone secretion during the estrous cycle and early pseudopregnancy in the rat: prolactin, gonadotropin and steroid levels associated with rescue of the corpus luteum of pseudopregnancy Endocrinology 96 219-226

Wuttke W and Meites J (1971) Evidence for a luteolytic function of prolactin during the estrous cycle of the rat Proceedings of the Society for Experimental Biology and Medicine 137 988-991

Received 26 January 2001.

First decision 29 March 2001.

Accepted 4 May 2001. 